Research Paper

International Journal of Medical Sciences

ISSN 1449-1907 www.medsci.org 2007 4(2):94-97

(c) Ivyspring International Publisher. All rights reserved

\title{
Alterations in Arterial Blood Parameters in Patients with Liver Cirrhosis and Ascites
}

\section{Konstantinos Charalabopoulos ${ }^{1,2}$, Dimitrios Peschos 3 , Leonidas Zoganas 4 , George Bablekos ${ }^{4}$, Christos Golias $^{1}$, Alexander Charalabopoulos ${ }^{1}$, Dimitrios Stagikas ${ }^{1}$, Angi Karakosta ${ }^{1}$, Athanasios Papathanasopou- los $^{5}$, George Karachalios², Anna Batistatou ${ }^{3}$}

1. Department of Physiology, Clinical Unit, Medical Faculty, University of Ioannina, Ioannina, Greece.

2. Department of Medicine, Red Cross Hospital, Athens, Greece.

3. Department of Pathology, Medical Faculty, University of Ioannina, Ioannina, Greece.

4. Department of Thoracic Surgery, Red Cross Hospital, Athens, Greece.

5. Department of Medicine, Gastroenterology Unit, Medical Faculty, University of Ioannina, Ioannina, Greece.

Correspondence to: Associate Professor K.A. Charalabopoulos, MD, PhD., Department of Physiology, Clinical Unit, Medical Faculty, University of Ioannina, 13, Solomou str. 45221 Ioannina, Greece. Tel: 0032651097574 Fax: 0032651097850 e-mail: kcharala@cc.uoi.gr

Received: 2006.09.08; Accepted: 2007.03.01; Published: 2007.03.06

In cirrhotic patients, in addition to hepatocytes and Kuppfer cells dysfunction circulatory anatomic shunt and ventilation/perfusion $\left(\mathrm{V}_{\mathrm{A}} / \mathrm{Q}\right)$ ratio abnormalities can induce decrease in partial pressure of oxygen in arterial blood $\left(\mathrm{PaO}_{2}\right)$, in oxygen saturation of hemoglobin $\left(\mathrm{SaO}_{2}\right)$ as well as various acid-base disturbances. We studied 49 cases of liver cirrhosis (LC) with ascites compared to 50 normal controls. Causes were: posthepatic 37 (75.51\%), alcoholic $7(14.24 \%)$, cardiac $2(4.08 \%)$, and cryptogenic $3(6.12 \%)$. Complications were: upper gastrointestinal bleeding $24(48.97)$, hepatic encephalopathy $20(40.81 \%)$, gastritis $28(57.14 \%)$, hepatoma $5(10.2 \%)$, renal hepatic syndrome $2(4.01 \%)$, HbsAg $(+) 24(48.97 \%)$, and hepatic pleural effusions 7 (14.28\%). Average $\mathrm{PaO}_{2}$ and $\mathrm{SaO}_{2}$ were $75.2 \mathrm{mmHg}$ and $94.5 \mathrm{mmHg}$, respectively, compared to $94.2 \mathrm{mmHg}$ and $97.1 \mathrm{mmHg}$ of the control group, respectively ( $\mathrm{p}$ value in both $\mathrm{PaO}_{2}$ and $\mathrm{SaO}_{2}$ was $\mathrm{p}<0.01$ ). Respiratory alkalosis, metabolic alkalosis, metabolic acidosis, respiratory acidosis and metabolic acidosis with respiratory alkalosis were acid-base disturbances observed. In conclusion, portopulmonary shunt, intrapulmonary arteriovenous shunt and $\mathrm{V}_{\mathrm{A}} / \mathrm{Q}$ inequality can induce a decrease in $\mathrm{PaO}_{2}$ and $\mathrm{SaO}_{2}$ as well as various acid-base disturbances. As a result, pulmonary resistance is impaired and patients more likely succumb to infections and adult respiratory distress syndrome.

Key words: liver cirrhosis, ascites, acid base disturbances, hepatopulmonary syndrome

\section{Introduction}

The arterial blood of some patients with cirrhosis is not fully saturated with oxygen, probably as a result of an admixture of venous with arterial blood and under- ventilation of some alveoli [1]. There are well known right-to-left anatomic shunts demonstrable between vessels that carry venous blood and those that carry oxygenated blood in the lungs. Arteriovenous shunt may be congenital e.g. in hereditary hemorrhagic teleangiectasia (Rendu Osler Weber disease) where the lesion is transmitted as a simple non-sex-linked dominant and the disorder is observed in the lungs as single or multiple lesions, or may be acquired [2]. Intrapulmonary arteriovenous shunt and portopulmonary shunt may be acquirely observed in patients with chronic liver disease $[3,4,5,6]$.

Hepatopulmonary syndrome refers to the triad of liver disease, pulmonary vascular dilation, and reduced arterial oxygenation [7]. While marked manifestations of the syndrome are unusual in patients with chronic liver disease, more subtle abnormalities of oxygenation are common. The abnormalities have been attributed to right-to-left shunts through pul- monary arteriovenous fistulas and development of bronchial varices in association with pulmonary hypertension. The syndrome occurs in chronic liver disease of all types and is more common in those with severe liver disease. Furthermore, portopulmonary shunt is another mechanism inducing blood gas alterations observed in patients suffering from severe chronic liver cirrhosis with ascites [8]. It is well known that portal hypertension has an important role in the formation of ascites by raising hydrostatic pressure within the splanchnic capillary bed. Ascites is most frequently encountered in patients with cirrhosis and other forms of severe liver disease. The clinical course of patients with advanced cirrhosis is often complicated by a number of important sequelae that are independent of the etiology of the underlying liver disease. These include portal hypertension with its consequences (e.g. gastroesophageal varices and splenomegaly), ascites, hepatic encephalopathy, spontaneous bacterial peritonitis, hepatorenal syndrome, hepatopulmonary syndrome, hepatocellular carcinoma as well as some other sequelae. In some patients with massive ascites, pleural effusion is 
common but even without it, pulmonary collapse and atelectasis may lead to arterial undersaturation since some alveoli are underventilated or not ventilated at all.

As a result of all those above described abnormalities the prognosis is poor on the basis of both the pulmonary and hepatic disease in patients with severe liver cirrhosis and ascites.

\section{Methodology}

Forty-nine (49) patients without any cardiopulmonary disease with liver cirrhosis and ascites (35 males, 14 females, ratio 2.5:1 and average mean age 65 years with age range $42-81$ years) were enrolled in the study. A group of fifty (50) healthy individuals consisted the control group. Cirrhosis had been diagnosed by history, clinical examination, laboratory findings, and liver biopsy, which all patients underwent. From a clinical point of view the patients' conditions varied from moderate to severe according to the Child-Pugh classification (B, C class). None of the patients complained of dyspnea. Patients with parenchymal lung disease were excluded from the study. Furthermore, none of them presented diagnostic criteria for asthma, chronic bronchitis, or emphysema according to the American Thoracic Society Directions.

Since classification of the various types of cirrhosis based on either etiology or morphology alone is unsatisfactory, we usefully classified the studied patients by a mixture of etiologically and morphologically defined entities based on clinical, pathological, and other data as follows: posthepatic 37 cases $(75.51 \%)$, alcoholic 7 cases $(14.24 \%)$, cardiac 2 cases $(4.08 \%)$, and cryptogenic 3 cases $(6.12 \%)$. The term posthepatic, synonymously to postnecrotic or multilobular cirrhosis, has been used in cases of cirrhosis resultant to viral hepatitis or infectious diseases, autoimmune hepatitis, inherited and metabolic disorders, as well as to drugs and toxins. In particular, based on epidemiologic and serologic evidence (HBsAg, HBeAg, anti-HbC, HBV-DNA) the vast majority of posthepatic cases was due to viral hepatitis (35 cases, $94.59 \%$ ), due mostly to type B (26 cases, $74.28 \%$ ), or type C (7cases, $20 \%$ ), and concomitant presence in 2 cases $(5.71 \%)$. Similarly, the term cryptogenic cirrhosis has been used in cases in which the etiology of the cirrhosis was unknown.

Complications observed in the patients studied were: upper gastrointestinal (UGI) bleeding in 20 cases $(48.97 \%)$, hepatic encephalopathy 20 cases $(40.81 \%)$, gastritis 28 cases $(57.14 \%)$, hepatoma 5 cases $(10.2 \%)$, hepatorenal syndrome 2 cases $(4.01 \%)$, HbsAg (+) 24 cases $(48.97 \%)$, and hepatic pleural effusions 7 cases (14.28\%). Table 1 and table 2 summarize patients classification and complications observed.

Partial pressure of oxygen in arterial blood $\left(\mathrm{PaO}_{2}\right)$, oxygen saturation of hemoglobin $(\mathrm{SaO} 2)$ as well as various acid-base disturbances were determined in all patients and normal controls as well. Arterial blood samples were taken while patients were breathing room air $\left(\mathrm{FiO}_{2}: 21 \%\right)$ in a half seated position. They underwent a puncture from the radical artery. $\mathrm{PaO}_{2}$ was immediately measured as well as carbon dioxide tension $\left(\mathrm{PaCO}_{2}\right)$ and oxyhemoglobin saturation $\left(\mathrm{SaO}_{2}\right)$.

Table 1. Classification of patients of the study.

\begin{tabular}{|c|c|c|}
\hline Etiology of the disease & $\mathrm{Nr}$ & $\%$ \\
\hline posthepatic & 37 & 75.51 \\
\hline alcoholic & 7 & 14.24 \\
\hline cardiac & 2 & 4.08 \\
\hline cryptogenic & 3 & 6.12 \\
\hline Total & 49 & 100 \\
\hline
\end{tabular}

Table 2. Complications of the cirrhotic patients under study.

\begin{tabular}{|c|c|c|}
\hline UGI bleeding & $\mathrm{Nr}$ & $\%$ \\
\hline Hepatic encephalopathy & 24 & 48.97 \\
\hline Gastritis & 20 & 40.81 \\
\hline Hepatoma & 28 & 57.14 \\
\hline Hepatorenal syndrome & 5 & 10.2 \\
\hline Hbs Ag + & 2 & 4.01 \\
\hline Hepatic pleural effusion & 24 & 48.97 \\
\hline Accompanied acid base disturbances & 7 & 14.28 \\
\hline Respiratory alkalosis & & \\
\hline Metabolic alkalosis & 22 & 44.89 \\
\hline Metabolic acidosis & 7 & 14.28 \\
\hline Respiratory acidosis & 3 & 6.12 \\
\hline Metabolic acidosis + respiratory alkalosis & 3 & 6.12 \\
\hline Normal acid base balance & 4 & 8.16 \\
\hline
\end{tabular}

\section{Results}

A $\mathrm{PaO}_{2}$ of equal or less than $80 \mathrm{mmHg}$ was defined as hypoxemia values. Values taken from the patients group were as low as below $80 \mathrm{~mm} \mathrm{Hg}$ with an average $\mathrm{PaO}_{2}$ of $75.2 \mathrm{~mm} \mathrm{Hg}$ while that in fifty healthy controls was $94.2 \mathrm{~mm} \mathrm{Hg}$.

Statistically, a significant difference was found $(p<0.01)$ between those compared groups. $\mathrm{SaO}_{2}$ values were in average $94.5 \mathrm{~mm} \mathrm{Hg}$ and $97.1 \mathrm{~mm} \mathrm{Hg}$, respectively, showing also a statistically significant difference $(p<0.01)$. Furthermore, a weak relationship between $\mathrm{PaO}_{2}$ and Pugh score was found in the patients group. Mean arterial $\mathrm{PaCO}_{2}$ in the patients group was 33.9 \pm 1.5 $\mathrm{mmHg}$ with hypocapnia most frequently found.

Acid-base disturbances observed were: respiratory alkalosis in 22 cases (44.89\%), metabolic alkalosis in $7(14.28 \%)$, metabolic acidosis in $3(6.12 \%)$, respiratory acidosis in $3(6.12 \%)$, and metabolic acidosis with respiratory alkalosis in $4(8.16 \%)$. Normal acid base balance was observed in $10(20.40 \%)$. Breath rate frequency in all patients studied, was within the normal rates; thus, acid-base disturbances could not be attributed solely to breath frequency abnormalities (e.g. respiratory alkalosis in patients with tachypnea).

Tables 1 and 2 show the classification of patients regarding the etiology of their disease as well as complications and acid based disturbances observed. None of the complications observed was attributed to drugs administered.

\section{Discussion}

Mild hypoxemia occurs in approximately one-third of patients with chronic liver disease. Arte- 
rial venous anastomoses and communications between the portal and arterial circulation as well as between bronchial and pulmonary veins are more likely to be functional in patients with cirrhosis and account for hypoxemia, as well as for perfusion defects seen on lung scan in patients with cirrhosis [9].

Shunts observed in patients with severe liver disease resulting in blood gas alterations may be contributed to portopulmonary shunt due to the portal hypertension development as well as to intrapulmonary arteriovenous shunt and $V_{A} / Q$ inequality. Hepatopulmonary syndrome, an infrequent complication of chronic liver disease usually associated with portal hypertension and cirrhosis, is manifested by dyspnea, platypnea and orthopnea and nowadays is more widely diagnosed occurring in chronic liver disease of all types and mainly in severe suffering patients $[4,9$, $10,11]$.

Liver cirrhosis is often accompanied by arterial hypoxemia in the absence of cardiopulmonary disease but the natural history of this syndrome is unknown. This fact was initially thought to be associated with the severity of the liver disease [12]. None of the patients enrolled in our study presented dyspnea and/or chronic lung disease according to the American Thoracic Society Directions. However, spirometric tests performed in all patients studied, confirmed the issue under discussion. Although putative mechanisms of hypoxemia include an intra- or extrapulmonary shunt, ventilation - perfusion inequality, and alveolar capillary diffusion limitation, there is a lack of agreement on which factors are the most important [13]. To the majority of cirrhotic patients that present dyspnea, this appears to be a consequence of ascites, hepatic hydrothorax or cardiopulmonary diseases. A wide spectrum of pulmonary gas exchange abnormalities may be found in patients with advanced liver disease [14]. The most frequent alteration of gas exchange in cirrhosis is hypocapnia observed in approximately $73 \%$ of cirrhotic patients which is associated with pulmonary vasodilatation. We hypothesize that hypocania, in association with vasodilating substances such as nitric oxide (NO) and endothelins, may contribute- at least in part- in the induction of hypoxemia. Pulmonary vasodilatation is even more frequent and severe in patients with advanced hepatocellular dysfunction. Intrapulmonary vasodilatation found in cirrhosis is thought to be at least partly involved in the development of hypoxemia, though some studies are arguing whether or not hypoxemia develops in patients with intrapulmonary vasodilatation $[15,16]$. In our study all of patients with cirrhosis (Child-Pugh B and C) had hypoxemia.

Contradictory, according to another study, the factor mostly inducing hypoxemia in liver cirrhosis is not the disease severity or the abnormal pulmonary circulation but rather the alcoholic etiology of cirrhosis [16]. Furthermore, according to similar studies the smoking status frequently coexisting in alcoholics had no significant effect on pulmonary functions in patients with liver diseases [16, 17]. Hypoxemia observed in alcoholic cirrhosis does not seem to be caused by alcohol induced disorders in the extrahepatic organs. It seems rather to be associated with an accelerated hyperdynamic and hypermetabolic circulatory state that favors hypoxemia $[18,19]$. All patients with alcoholic cirrhosis studied, herein, (7 out of $49,14.24 \%$ ) were in a hypoxemic state. Several studies support this assumption suggesting that an increased oxygen demand due to excess alcohol consumption is the primary cause of hypoxemia in alcoholic patients [19]. Moreover, in these series of patients none presented with dyspnea or clinical signs of hepatopulmonary syndrome. These findings confirm previous clinical investigations that illustrated hypoxemia is a common finding in patients with cirrhosis particularly in those with Child-Pugh grade $C$, (grade < 14), in whom, furthermore, clinical manifestations were rare [20-23]. According to previously published studies, concerning patients with liver cirrhosis, the incidence of hypoxemia appeared to be high in Child-Pugh grade C, presenting a slight difference with those patients classified as grade A or B $[12,23]$. Results of the present study coincide with these reports published earlier. The weak link between $\mathrm{PaO}_{2}$ and Pugh score found herein, suggests that other mechanisms apart from $\mathrm{PaO}_{2}$, are involved in the cirrhosis associated hypoxemia mechanisms.

Chronic liver disease, arterial deoxygenation and widespread intrapulmonary vasodilatation characterize the hepatopulmonary syndrome [22]. In decompensate cirrhotic patients, there is an increased arteriovenous shunt for oxygen in the lower extremities that is associated with increased arterial blood flow, decreased systemic vascular resistance and worsening of the liver function. This shunt is due at least partly to the opening of arteriovenous precapillary connections [24]. No any treatment is clinically useful, thus, at present the only treatment resulting to the resolution of the syndrome with simultaneous correction of the blood gas oxygenation alterations is the orthotopic liver transplantation.

Fluid in the chest (pleurisity) may be found in at least 10 percent of patients with cirrhosis, being more common on the right side influencing when in large quantities the $V_{A} / Q$ ratio. In the present study 7 patients $(14.28 \%)$ presented pleurisity. Hypoxemia usually appears to be worse in standing than in supine position. Oxygen administration improves dyspnea but does not reverse the defects in some patients [25]. Embolization of shunts if it is possible may be useful.

Gastrointestinal hemorrhage, in the type of variceal bleeding represents a common complication of chronic liver disease and is associated with a high mortality. Studies carried out in a cirrhotic rat model suggested that blood volume restitution following hemorrhage, produce an increase in portal pressure above the limit of the basal values in animals with high portal systemic shunting [26]. Additionally, a number of studies have shown that patients with alcoholic liver disease are known to have a variable and occasionally extensive degree of portosystemic shunting ranging from $5-70 \%[25,26]$. It must be mentioned that all pa- 
tients' medicines were always administrated with caution, especially those eliminated or modified through hepatic metabolism or biliary pathways. In particular, care was taken in order to avoid precipitating complications of cirrhosis due to overzealous use of drugs such as vigorous treatment of ascites with diuretics that might result in electrolyte abnormalities or hypovolemia. Similarly, sedatives even in modest doses were not used in the patients; so that encephalopathy observed in some patients studied herein, could not be attributed to such a use.

\section{Conclusions}

In conclusion, in patients suffering from severe liver cirrhosis and ascites, portopulmonary shunt, intrapulmonary shunt and $\mathrm{V}_{\mathrm{A}} / \mathrm{Q}$ inequality may induce a decrease in $\mathrm{PaO}_{2}$ and $\mathrm{SaO}_{2}$ in association with various acid-base disturbances. As a result, pulmonary resistance is impaired and patients more likely succumb to infections and adult respiratory distress syndrome. Thus, prognosis in those patients is poor on the basis of both hepatic and pulmonary disease.

\section{Conflict of interest}

The authors have declared that no conflict of interest exists.

\section{References}

1. Aller R, Moya J, Moreira V, Boixeda D, Picher J, Garcia-Rull S, De Luis D. Etiology and frequency of gas exchange abnormalities in cirrhosis. Rev Esp Enterm Dig. 1999; 91: 559-568.

2. Dines D, Arms RA, Bernatz Re. Pulmonary arteriovenous fistulas. Mayo Clinic Proc. 1975; 49: 460-471.

3. Vlavianos P, Mac Mathuna P, Williams R, Westaby D. Splanchnic and systemic haemodynamic response to volume changes in patients with cirrhosis and portal hypertension. Clin Sci (Colch). 1999; 96: 475-481.

4. Denie C, Vachiery F, Gadano A, Sogni P, Elman A, Moreau R, Valla D, Lebrec D. Influence of transjugular intrahepatic portosystemic shunts (TIPS) on tissue oxygenation in patients with cirrhosis. Liver 1998; 18: 239-244.

5. Duranti R, Laffi G, Misuri G, Riccardi D, Gorini M, Foschi M, Iandelli I, Mazzanti R, Mancini M, Scano G, Gentilini P. Respiratory mechanics in patients with tense cirrhotic ascites. Eur Respir J. 1997; 10: 1622-1630.

6. Fernandez-Rodriguez CM, Prieto J, Zozaya JM, Quiroga J, Guitian R. Arteriovenous shunting, hemodynamic changes, and renal sodium retention in liver cirrhosis. Gastroenterology 1993; 104: 1139-1145.

7. De BK, Sen S, Biswas PK, Biswas J, Maity AK. Clinical and haemodynamic aspects of hepatopulmonary syndrome in Indian patients with cirrhosis. J Gastroenterol Hepatol. 2000; 15: 412-416.

8. Nagral A, Kolhatkar VP, Bhatia SJ, Taskar VS, Abraham P. Pulmonary function tests in cirrhotic and non-cirrhotic portal hypertension. Indian J Gastroenterol. 1993; 12: 36-40.

9. Stanley N, Ackrill B, Wood J. Lung perfusion scanning in hepatic cirrhosis. Br Med J. 1972; 4: 639-643.

10. Muller C, Shen KP. Hepatopulmonary syndrome. Wien Klin Wochenschr. 1999; 111: 339-347.

11. Martinez G, Barbera JA, Navasa M. Hepatopulmonary syndrome associated with cardiorespiratory disease. J Hepatol. 1999; 30: 882-889.

12. Vachiery F, Moreau R, Hadengue A, Gadano A, Soupison T, Valla D, Lebrec D. Hypoxemia in patients with cirrhosis: rela- tionship with liver failure and hemodynamic alterations. J Hepatol. 1997; 27: 492-495.

13. Krowka MJ. Pulmonary aspects of chronic liver disease and liver transplantation. Mayo Clinic Proc. 1985; 60: 407-418.

14. Martinez GP, Barbera JA, Visa J, Rimola A, Pare JC, Roca J, Navasa M, Rodes J, Rodriguez-Roisin R. Hepatopulmonary syndrome in candidates for liver transplantation. J Hepatol. 2001; 34: 651-657.

15. Abrams GA, Jaffe CC, Hoffer PB, Binder HJ, Fallon MB. Diagnostic utility of contrast echocardiography and lung perfusion scan patients with hepatopulmonary syndrome. Gastroenterology 1995; 109: 1283-1288.

16. Shingeo M, Chisato H, Nobuyuki O, Yoshiro K, Kensuke U, Atsushi S, Kazuhiro K, Katsuhiko F, Hirashi K, Yasufumi O. Prevalence of hypoxemia in 102 Japanese patients with alcoholic and nonalcoholic cirrhosis. Am J Gastroenterol. 1999; 94: 2994-2999.

17. Hourani JM, Bellamy PE, Tashkin DP, Batra P, Simmons MS. Pulmonary dysfunction in advanced liver disease: Frequent occurrence of an abnormal diffusing capacity. Am J Med. 1991; 90: 693-700.

18. Luca A, Garcia-Pagan JC, Bosch J, Feu F, Caballeria J, Groszmann RJ, Rodes J. Effects of ethanol consumption on hepatic hemodynamics in patients with alcoholic cirrhosis. Gastroenterology 1997; 112: 1284-1289.

19. Silva G, Fluxa F, Bresky G, Backhouse C, Palma M, Ruiz M, Hirsch S, Iturriaga H. Splanchnic and systemic hemodynamics in early abstinence and after ethanol administration in non-cirrhotic alcoholic patients. J Hepatol.1994; 20: 494-499.

20. Fallon MB, Abrams GA. Pulmonary dysfunction in chronic liver disease. Hepatology 2000; 32: 859-865.

21. Krowka M. Hepatopulmonary syndromes. Gut 2000; 46: 1-4.

22. Schenk P, Schoniger-Hekele M, Fuhrmann V, Madl C, Silberhumer G, Muller C. Prognostic significance of the hepatopulmonary syndrome in patients with cirrhosis. Gastroenterology 2003; 125: 1042-1052.

23. Herve P, Lebrec D, Brenot F, Simonneau G, Humbert M, Sitbon O, Duroux P. Pulmonary vascular disorders in portal hypertension. Eur Respir J 1998; 11: 1153-1166.

24. Fernandez-Rodriguez CM, Prieto J, Zozaya JM, Quiroga J, Gui$\tan$ R. Arteriovenous shunting, hemodynamic changes, and renal sodium retention in liver cirrhosis. Gastroenterology. 1993; 104: 1139-1145.

25. Sakurabayashi S, Sezai S, Yamamoto Y, Hirano M, Oka H. Embolisation of portal-systemic shunts in cirrhotic patients with chronic reccurent hepatic encephalopathy. Cardiovasc Intervent Radiol. 1997; 20: 120-124.

26. Kravetz D, Bosch J, Arderiu M, Pilar Pizcueta M, Rodes J. Hemodynamic effects of blood volume restitution following a hemorrhage in rats with portal hypertension due to cirrhosis of the liver: influence of the extent of portal-systemic shunting. Hepatology 1989; 9: 808 -814.

27. Groszmann RJ, Kotelanski B, Cohn JN, Khatri IM. Quantification of portasystemic shunting from the splenic and mesenteric beds in alcoholic liver disease. Am J Med. 1972; 53: 715-722.

28. Okuda K, Susuki K, Musha H, Arimizu N. Percutaneous transhepatic catheterization of the portal vein for the study of portal hemodynamic and shunts. Gastroenterology 1977; 73: 279-284.

29. Okhubo H, Okuda K, Iida S, Ohnishi K, Ikawa S, Makino I. Role of portal and splenic vein shunts and impaired hepatic extraction in the elevated serum bile acids in liver cirrhosis. Gastroenterology 1984; 86:514-520. 